\title{
El principio de laicidad: el caso del velo islámico
}

\author{
CORINA YTURBE \\ Instituto de Investigaciones Filosóficas \\ Universidad Nacional Autónoma de México \\ yturbe@servidor.unam.mx
}

\begin{abstract}
Resumen: En el retorno del tema de la laicidad parecen ponerse en duda sus propios principios. En este artículo se analiza cuáles son esos principios para aclarar qué es lo que se está defendiendo o atacando cuando se habla de "laicidad". Para ello se toma como punto de referencia el debate francés suscitado por el uso del velo islámico en las escuelas, así como el documento elaborado al respecto por la "Comisión de reflexión sobre la aplicación del principio de la laicidad en la República", formada por políticos, filósofos, científicos sociales y presidida por el ministro Bernard Stasi. Ese informe nos ofrece la versión francesa de la laicidad y sus problemas en la actualidad.

Palabras clave: estado laico, tolerancia religiosa, neutralidad, igualdad
\end{abstract}

\begin{abstract}
Recent debates on the concept of laicism (laïcité) seem to challenge the principles on which that concept is based. The article analyses those principles, in order to clarify what is at stake when we talk about laïcité. The point of reference is the debate that recently emerged in France over the use of the Islamic foulard in public schools and, in particular, the report produced by the "Stasi Comission", a group of politicians, philosophers and social scientists, under the leadership of minister Bernard Stasi. That report offers a French view of the problems laïcité faces in contemporary societies.
\end{abstract}

Key words: laic state, religious tolerance, neutrality, equality

\section{El asunto del velo islámico}

Ante lo que se consideraba como ataques graves y comportamientos amenazantes frente a la laicidad, la Comisión Stasi convocó a toda la sociedad francesa a participar en el debate sobre el principio de laicidad. Se escucharon así las opiniones de un amplio abanico de grupos y de individuos, ${ }^{1}$ incluidas las mujeres musulmanas que usan el velo y

${ }^{1}$ Participaron en esa gran consulta responsables de los partidos políticos, miembros del gobierno, representantes de las distintas religiones y opciones filosóficas, responsables sindicales, asociaciones de defensa de los derechos humanos, directores de escuelas, hospitales y prisiones, comisarios de policía, jefes de empresas, alumnos, mujeres islámicas, etc. Cfr. Comisión Stasi, "Le Rapport de la Commission Stasi sur la Laïcité".

Diánoia, volumen LI, número 56 (mayo 2006): pp. 67-93. 
otras que se rehúsan a usarlo. ${ }^{2}$ Se trataba de ofrecer un diagnóstico y de proponer alguna solución para garantizar el respeto del principio de la laicidad. El 11 de diciembre de 2003 la Comisión Stasi entregó su informe al presidente Jacques Chirac. El documento no se limita al análisis del supuesto cuestionamiento de la noción de laicidad por el uso del velo islámico, ni a la laicidad como doctrina fundamental de la educación nacional en Francia, sino que abarca múltiples aspectos económicos, políticos y sociales, ofreciendo en cada caso recomendaciones para reforzar el principio de laicidad, considerado como un "valor fundador" de la República Francesa. Sin embargo, el presidente Chirac sólo tomó en consideración la cuestión del uso del velo islámico, el hiyab, proponiendo una ley que prohibía su uso en las escuelas francesas. También se proscribieron otros símbolos religiosos "ostensibles", como la kippa y las grandes cruces cristianas. Pero es el hiyab lo que se encuentra en el centro del debate. ${ }^{3}$ La Asamblea Nacional aprobó el proyecto de ley, que entró en vigor en septiembre de 2004: "En las escuelas primarias, secundarias y liceos públicos, el uso de signos o prendas mediante los cuales los alumnos manifiesten ostensiblemente una pertenencia religiosa deben ser proscritos." 4

En Francia, la tradición de laicidad parece ser más fuerte que en otros países, en la medida en que el principio de laicidad está inscrito en el artículo primero de la Constitución francesa. Sin embargo, la mayor parte de los estados democráticos reivindica principios de laicidad, sobre todo en lo que concierne a la libertad religiosa de los ciudadanos, aun cuando no hayan inscrito en su Constitución la laicidad del

\footnotetext{
${ }^{2}$ Durante el debate, las mujeres musulmanas han dado sus razones para usar o no el velo. Algunas utilizan argumentos feministas para justificar su decisión: para ellas, el velo simboliza la sumisión de las mujeres en el Islam. Otras utilizan argumentos similares para justificar una posición opuesta: para ellas, usar el velo libera a la mujer de la mirada concupiscente de los hombres, que tratan a las mujeres con mayor igualdad si se eliminan todos los signos de atracción sexual. (Cfr. A. Giddens, "Voile islamique: la France sur la mauvaise voie").

${ }^{3}$ La lucha en torno al hiyab no es una preocupación exclusivamente francesa, sino que existe en varios países y tiene una larga historia; algunos estados de Alemania están considerando introducir una ley similar a la francesa. La laicidad heredada de Atatürk prohíbe el uso del hiyab en la universidad turca; su uso también estaba prohibido en Irán en la época del sha (ahora es obligatorio). En Indonesia, en la época de Suharto, hasta principios de los años 1990, el vestido islámico era considerado como un signo de ignorancia, de arcaísmo, y se efectuaba una disuasión activa en las escuelas ( $C f r$. A. Giddens, op. cit.).

${ }^{4}$ Artículo 141-5-1 de la Ley no. 2004-228 del 15 de marzo de 2004, Journal Officiel de la République Française, 17 de marzo de 2004.
}

Diánoia, vol. LI, no. 56 (mayo 2006). 
estado: "el modelo laico se ha vuelto prácticamente indispensable en las sociedades religiosamente plurales y diversas, que desean desarrollar un marco de libertades y pacífica convivencia" ${ }^{5}$. Sin embargo, justo por tratarse de "un modelo de convivencia política en detrimento de la influencia social de las instituciones religiosas", existe una gran confusión en torno al término laicidad: casi siempre se identifica de manera exclusiva con la separación del Estado y las Iglesias; en general se hace referencia a los valores de respeto, de diálogo y de tolerancia, y de ese modo la laicidad queda vinculada al reconocimiento de la pluralidad religiosa y al respeto de los derechos humanos; otras veces se identifica como un modelo específico del pensamiento occidental, ligado a la ideología liberal y a la Ilustración y, por tanto, estrechamente vinculado al valor de la tolerancia, así como a la neutralidad del estado.

Una manera de aclarar qué es la laicidad y cuáles son sus elementos esenciales es partir del surgimiento histórico del estado laico. Al analizar los principios de la laicidad propuestos por la comisión buscaré mostrar, por un lado, la diferencia entre el concepto de laicidad y algunas de las nociones o ideas con las que generalmente se le relaciona: separación Estado-Iglesias, tolerancia religiosa, libertad de conciencia; por otro lado, será necesario referirse, aunque sea brevemente, a las nociones de espacio público y neutralidad del estado.

\section{2. ¿Laicidad o laicismo?}

En la actualidad son cada vez más discutidos, pero no con frecuencia diferenciados, los dos conceptos de "laicismo" y "laicidad". En el documento de la Comisión Stasi, se utiliza siempre el término "laicidad"; 6 sin embargo, en la traducción al español del reporte de la comisión se

\footnotetext{
${ }^{5}$ R. Blancarte, "Definir la laicidad (desde una perspectiva mexicana)", p. 15.

${ }^{6}$ Roberto Blancarte sostiene que los franceses fueron los que inventaron el neologismo "laicidad" ("Definir la laicidad (desde una perspectiva mexicana)", p. 15). En este mismo sentido, Jean Baubérot afirma que "el término laicidad, en su sentido moderno, es una invención francesa" (J. Baubérot, Historia de la laicidad francesa, p. 15). Asimismo, Catherine Kintzler señala que el concepto de laicidad moderna es una invención francesa de Ferdinand Buisson (1848-1952) (C. Kintzler, Tolérance et laïcité, p. 7). Sin embargo, todos estos autores no consideran que la laicidad sea una "excepción francesa": "la laicidad es un valor universal, y la francesa no es más que un caso particular de aquélla" (J. Baubérot, op. cit., p. 15). Hay que señalar que la preocupación por el principio de laicidad se presenta sobre todo en los estados donde la religión católica es la predominante. En Francia, la separación de la Iglesia y el Estado tuvo que esperar hasta el siglo xx. En los países donde el protestantismo era la religión dominante, el desplazamiento de la religión del espacio público se
} 
utiliza "laicidad" o "laicismo" de manera indistinta; lo mismo ocurre en la voz "laicidad" en el Diccionario de política, que utiliza algunas veces el término laicismo en lugar del término laicidad, sin aclarar si existe o no alguna diferencia. ${ }^{7}$ Pero, si bien estos dos términos con frecuencia son utilizados de manera indistinta, algunos autores sí intentan establecer un sentido específico para cada uno de ellos. Blancarte, por ejemplo, define la laicidad como "la forma específica de convivencia social establecida precisamente a partir de la secularización de las instituciones públicas", mientras que el laicismo "tendería a ser identificado como una forma militante de quienes defienden este estado de cosas". ${ }^{8}$

Norberto Bobbio, por su parte, sostiene "que debe mantenerse la distinción entre los dos términos laicismo y laicidad". ${ }^{9}$ El primero generalmente es usado con una connotación negativa, para designar una posición de intransigencia y de intolerancia hacia los credos y las instituciones religiosas. En este sentido, pertenece a la categoría de los "ismos" (liberalismo, socialismo, marxismo...), es decir, se trataría de una visión global, omnicomprensiva, del mundo. Según él, cuando la laicidad se transforma en laicismo, "es contraria a su inspiración fundamental, que es la de no clausura de un sistema de ideas y de principios definidos de una vez y para siempre". ${ }^{10}$ En otras palabras, al utilizar el término "laicismo" así entendido se corre el riesgo de caer en la contradicción de un fanatismo o dogmatismo laico. El "laicismo", como oposición sistemática a toda influencia de la jerarquía religiosa sobre los hombres, sería justo lo contrario del espíritu laico o de la laicidad correctamente entendida: Bobbio concibe la laicidad "más como un método que como un contenido", ${ }^{11}$ como el ejercicio del espíritu crítico dentro de los límites de la razón. La laicidad es una cultura abierta, libre de dogmas y de doctrinarismos rígidos, y cuya característica fundamental es la tolerancia; sin embargo, comentando la concepción de Bobbio sobre este tema, E. Vitale señala que la contradicción de la que habla Bobbio es aparente:

Aunque podamos buscar soluciones de compromiso para cada coyuntura histórica, el motivo último de una batalla intelectual laica debe ser la

dio en otros términos y no implicó la desaparición de la religión de la vida pública, como es el caso de Estados Unidos.

${ }^{7}$ Cfr. Comisión Stasi, op. cit., y V. Zanone, "Laicismo", p. 885.

${ }^{8}$ R. Blancarte, "Introducción", p. 8.

${ }^{9}$ N. Bobbio, "La tolleranza positiva", p. 12.

${ }^{10}$ N. Bobbio, "Cultura laica, una terza cultura?"

${ }^{11}$ Ibid., p. 39-40.

Diánoia, vol. LI, no. 56 (mayo 2006). 
derrota, o al menos la denuncia, del prejuicio y de la superstición que son la esencia de las religiones históricas y de la tradición. [.. . ] En mi interpretación, laicismo y laicidad son una adhesión al espíritu de la Ilustración que podemos resumir del siguiente modo: no recurrir al principio de autoridad, no iurare in verba magistri... ${ }^{12}$

Según esta concepción, el significado más profundo de la laicidad consistiría "no tanto en la oposición a las religiones históricas y a toda creencia en lo sobrenatural, sino más bien en la oposición a toda forma de doctrinarismo, dogmatismo u ortodoxia". ${ }^{13}$ Si se evita caer en la contradicción de la que habla Bobbio de un fanatismo o dogmatismo laico, o de pensar este principio en una "forma militante", puede seguirse el consejo de Vitale de abandonar la distinción entre laicidad y laicismo. Ambos vocablos se refieren a la doctrina que defiende la independencia del hombre o de la sociedad, y más particularmente del estado, de toda influencia eclesiástica o religiosa. ${ }^{14}$

\section{Tolerancia y espacio público}

Por más que la laicidad haya sido identificada de manera unilateral con el anticlericalismo, el anticonfesionalismo, la irreligiosidad o el ateísmo, según Bobbio, "históricamente el espíritu laico ha producido una de las más grandes conquistas del mundo moderno, la tolerancia religiosa, de cuyo seno surgió la tolerancia de las ideas en general y por último de las opiniones políticas". ${ }^{15}$ Después de la revolución francesa y a partir de la Declaración de los derechos del hombre, lo que antes era objeto de tolerancia dejó de serlo, cuando por su relevancia pasó a ser considerado como un bien que jurídicamente debe ser protegido: es decir, las libertades de creencia, de opinión, de expresión, dejaron de ser objetos de tolerancia para convertirse en derechos, esto es, fueron reconocidas por las constituciones. ${ }^{16}$

La relación entre laicidad y tolerancia no está exenta de problemas. Al igual que la noción de laicidad, el concepto de tolerancia es una categoría histórica. ¿De qué hablamos cuando hablamos de tolerancia desde el principio de laicidad? Siguiendo a Bobbio, cuando la tolerancia se refiere a problemas morales, jurídicos y políticos, y no al ámbito

${ }^{12}$ E. Vitale, Derechos y paz. Destinos individuales y colectivos, p. 81.

${ }^{13}$ E. Vitale, "Laicità e religiosità nel pensiero di Norberto Bobbio".

${ }^{14}$ En lo que sigue usaré el término "laicidad".

${ }^{15}$ N. Bobbio, "Cultura laica, una terza cultura?", p. 39.

${ }^{16}$ Cfr. J. de Lucas, "¿Para dejar de hablar de la tolerancia?" 
de la vida cotidiana, encontramos dos significados referidos a dos órdenes de cuestiones parcialmente independientes:

Cuando se habla de tolerancia en su significado histórico predominante, se hace referencia al problema de la convivencia de las creencias diferentes, primero religiosas y después también políticas. Hoy, el concepto de tolerancia se extiende al problema de la convivencia de las minorías étnicas, lingüísticas, raciales; en general, de aquellos que llamamos los diferentes, como los homosexuales, los locos o los minusválidos, por ejemplo. Los problemas a los que se refieren estos dos modos de entender, de practicar y de justificar la tolerancia no son los mismos. Uno es el problema de la tolerancia de creencias u opiniones diferentes, que implica un discurso sobre la verdad y la compatibilidad teórica o práctica de verdades incluso contrapuestas; otro es el problema de la tolerancia de aquel que es diferente por razones físicas o sociales, un problema que pone en primer plano el tema del prejuicio y de la consiguiente discriminación. Las razones que se pueden invocar, y han sido efectivamente invocadas en los siglos en los que hervía el debate religioso, en defensa de la tolerancia en el primer sentido, no son las mismas que se invocan para defender el segundo. ${ }^{17}$

Podemos decir, entonces, que el principio de laicidad tuvo que ver en sus orígenes con el primer sentido de tolerancia señalado por Bobbio, pero que cuando se discute ese principio en nuestros días, no sólo se hace referencia a la tolerancia entendida como la aceptación y defensa de la pluralidad de creencias y de opiniones, sino sobre todo a la tolerancia como aceptación de los otros, a la convivencia con o entre los diferentes.

Ahora bien, tolerancia en su sentido histórico preponderante no es la pura y simple abstención de la persecución, sino que

es una posición que se funda en la convicción de que la pluralidad de creencias y de las opiniones, sean religiosas o políticas, en competencia práctica entre ellas, es una condición esencial para la supervivencia y el desarrollo regular de una sociedad democrática, es decir, de una sociedad cuyos valores fundamentales, garantizados por la observación de reglas primarias, son la libertad, la igualdad y la no violencia. ${ }^{18}$

La tolerancia no es, pues, indiferencia, falta de interés, ignorancia, suspensión del juicio evaluativo, prudencia o resignación. No equivale a

${ }^{17}$ N. Bobbio, "Le ragioni della tolleranza", p. 235.

${ }^{18}$ N. Bobbio, "La tolleranza positiva", p. 12.

Diánoia, vol. LI, no. 56 (mayo 2006). 
soportar lo que creemos que son errores de los otros por razones de conveniencia, como un mal menor con respecto a la persecución violenta. $Y$ lo mismo vale para el segundo sentido: tolerancia implica aceptar algo aunque lo desaprobemos, por cuanto que se funda sobre el derecho a la libertad de los otros. El valor de la tolerancia se basa, en general, en el respeto a la autonomía del otro: la tolerancia es una actitud obligada en relación con cualquier elección autónoma, sin importar el disgusto que ésta pueda causar. Ello no implica identificar el principio de tolerancia únicamente con el "respeto a la diferencia"; como señala Ferrajoli: "el valor primario de la persona y consiguiente principio de tolerancia son, a mi juicio, los elementos constitutivos del moderno principio de igualdad jurídica: un principio complejo, que incluye las diferencias personales y excluye las diferencias sociales". ${ }^{19}$

No puede dejar de plantearse la pregunta sobre los límites de la tolerancia: "¿debemos tolerar también a los que actúan como intolerantes, o bien se debe oponer la intransigencia propia de una concepción de la tolerancia que no coincide con la indiferencia?" ${ }^{20}$ Sin embargo, en la realidad hay grados y manifestaciones distintas de intolerancia y, como señala Bobbio, responder al intolerante con la intolerancia es "éticamente pobre y quizá también políticamente inoportuno". ${ }^{21}$ El problema es cómo responder a prácticas culturales que se consideran intolerables, tales como, por ejemplo, las costumbres comunitarias que restringen las oportunidades de las mujeres, o las oportunidades de los niños para prepararse para una vida fuera de la comunidad de origen, o las que obligan a operaciones que son físicamente dolorosas. Si nuestro tiempo es, como dice Bobbio, el tiempo de los derechos, podemos argumentar que el criterio para fijar el alcance de la tolerancia debe identificarse con el principio de la autonomía individual que está en la base de los derechos humanos. Debemos afirmar la obligación de respetar los valores y las preferencias de los demás, pero ese respeto no excluye la posibilidad de discutir esos valores y esas preferencias.

En el caso que nos ocupa, el Estado francés reconoce el valor de la tolerancia y las instituciones políticas reconocen y contienen este valor. La tolerancia está directamente implicada en los arreglos políticos y en el diseño de las instituciones, a través de las cuales el estado puede prescribir y prohibir acciones públicas de manera legítima en ciertas áreas sociales. La tolerancia es entendida como uno de los elementos

\footnotetext{
${ }^{19}$ L. Ferrajoli, Derecho y razón. Teoría del galantismo penal, p. 906.

${ }^{20}$ E. Vitale, "Laicità e religiosità nel pensiero di Norberto Bobbio".

${ }^{21}$ N. Bobbio, "Le ragioni de la tolleranza", p. 249.
} 
que entran en la institucionalización de la igualdad jurídica y, en consecuencia, de la garantía del pluralismo, de la igualdad y de las libertades. El problema de tolerancia política surge, entonces, cuando la autoridad política se enfrenta a la cuestión de si ciertos tipos de prácticas o de comportamiento son objetos de no interferencia o de protección por parte del estado. La prohibición de usar el velo no es un caso de intolerancia por parte del Estado francés: no se está planteando el problema de libertad de conciencia o de pensamiento en términos de tolerancia, ya que se trata de derechos inscritos en la Constitución; es decir, derechos de cuya garantía es responsable el estado. Se trata más bien de una reafirmación de los límites de la esfera pública contra la interferencia de la religión.

En nuestra época, marcada por grandes flujos migratorios, el problema de la convivencia con los "otros" se ha convertido en uno de los grandes problemas de las democracias constitucionales. La coexistencia de distintas culturas ocasiona que ciertas prácticas produzcan conflictos al ser evaluadas interculturalmente: por ejemplo, privar a las niñas y jóvenes musulmanas de prácticas educativas, como las clases de deportes o de natación, o la insistencia de que las niñas usen el hiyab o velo. Estas prácticas particulares, que tienen que ver con el estatus de las mujeres en distintas comunidades culturales o con las maneras de vestirse, en general son vistas, en las modernas democracias liberales, como pertenecientes a la esfera doméstica o privada, en la cual el estado no debería tener ningún tipo de intervención.

En las sociedades liberales, la demarcación de lo privado y lo público puede resumirse señalando que el espacio político, junto con la economía y ciertos ámbitos de la sociedad civil, es "público" en múltiples sentidos: lo que es de interés común a todos, lo que es accesible a todos, lo manifiesto y ostensible, en contraposición a lo que es secreto, preservado, oculto. ${ }^{22}$ Estos tres sentidos tendían a coincidir en la imagen del estado como el lugar de lo común y lo general. Lo doméstico, donde tiene lugar lo que no es de interés común a todos, pertenecería al ámbito de lo "privado". En las sociedades liberales, los patrones institucionales que regulan la relación entre los espacios público y privado se basan en varias tesis. El liberalismo se basa en la convicción de que lo privado se extiende a todas las creencias que pertenecen a la religión, la cultura y el modo de vida. No sólo se respeta "la privacidad" de la esfera doméstica familiar; también requiere que el estado no regule asuntos

\footnotetext{
${ }^{22}$ N. Rabotnikof, En busca de un lugar común. El espacio público en la teoría política contemporánea, pp. 27-30.
}

Diánoia, vol. LI, no. 56 (mayo 2006). 
de creencias religiosas, culturales o modos de vida. Sin embargo, tanto la idea del estado como el lugar de lo general y lo común, como la línea que separa lo público de lo privado han dado lugar a redefiniciones del concepto de espacio público y a su desplazamiento hacia la sociedad civil. ${ }^{23}$ Como veremos más adelante, en el documento de la comisión, en su uso de la oposición público/privado, se intentará dar cuenta del pluralismo cultural y de la diversidad de prácticas culturales de los inmigrantes musulmanes.

\section{Valor histórico del principio de laicidad}

La laicidad no es un valor intemporal: como la mayoría de los conceptos políticos, ha sido moldeado por acontecimientos históricos, a través de los cuales su significado se ha ido enriqueciendo. No es una corriente de pensamiento entre otras o una "filosofía" en particular. La laicidad nunca se ha establecido como una construcción dogmática, sino que, por el contrario, nació como reacción a todo dogmatismo y luego se ha ido modificando de modo empírico, atenta a los acontecimientos históricos. ${ }^{24}$ Desde un punto de vista sociológico, pueden aprehenderse las diferentes acepciones de la laicidad relacionándola con los hechos políticos y sociales que fueron moldeando su significado hasta llegar a la familia actual de acepciones de este concepto.

Como movimiento político, el laicismo tenía como objetivo rechazar la hegemonía que tenía la Iglesia sobre el poder político durante la Edad Media. En la historia moderna, el término laicidad —al igual que el de tolerancia - se ha hecho valer contra el dominio de una religión. El Ensayo sobre la tolerancia de Locke es, ante todo, una defensa de la libertad religiosa; el Tratado sobre la tolerancia de Voltaire es un escrito contra el fanatismo religioso de unos jueces. En la acepción contemporánea, la laicidad adquiere su significado con la revolución francesa, a través de la afirmación de la autonomía de la conciencia en el plano religioso y en general espiritual. El artículo 10 de la Declaración de los

${ }^{23}$ Es imposible presentar en unas cuantas líneas todas las complicaciones implícitas en este tema: por un lado, la crisis del estado y el desplazamiento del espacio público hacia la sociedad civil, y, por otro, la multivocidad que caracteriza la línea que separa lo público de lo privado, la cual, debido fundamentalmente a transformaciones históricas, ha ido redefiniendo el espacio público y su relación con lo privado. Para un examen lúcido y riguroso sobre la noción de espacio público, véase N. Rabotnikof, op. cit.

${ }^{24}$ En este sentido, la Comisión Stasi se refiere a la laicidad francesa como a "un principio jurídico aplicado con empirismo". 
derechos del hombre y del ciudadano de 1789 afirma: "Nadie debe ser importunado por sus opiniones, incluso las religiosas, en tanto su manifestación no sea un problema para el orden público establecido por la ley." Con ello desaparecen las discriminaciones de orden religioso. Más adelante, con la Asamblea Legislativa, en 1792, la ciudadanía ya no se liga a la religión. ${ }^{25}$

En este momento, que Baubérot llama "el primer umbral de laicización", ${ }^{26}$ a partir de la Declaración de los derechos del hombre de 1789, surge la idea del estado laico, del estado neutro con respecto a los cultos, independiente del clero y de toda concepción teológica. El "estado laico" se refiere, así, al estado en que se prescinde de la enseñanza religiosa y, por extensión, al estado independiente de toda influencia religiosa, tanto en su constitución como en sus individuos. La noción de "estado laico" indica "lo contrario del estado confesional, es decir, del estado que adopta como propia una determinada religión y concede privilegios a los creyentes de ésta respecto de los creyentes de otras religiones y de los no creyentes". ${ }^{27}$ En el estado confesional, aunque no exista el monopolio eclesiástico, la religión sigue siendo la base para la legitimación del poder temporal: el rey fundamenta su legitimidad en el origen sagrado de su poder. En el estado laico, por el contrario, el poder ya no es legitimado por elementos religiosos, sino por la soberanía popular. De ahí que Blancarte proponga definir la laicidad como "un régimen social de convivencia, cuyas instituciones políticas están legitimadas principalmente por la soberanía popular y (ya) no por elementos religiosos". ${ }^{28}$ Sin embargo, este cambio de la imposibilidad de concebir ninguna autoridad que no estuviera basada en alguna realidad superior, y la comprensión de la vida social y política en tiempo secular, no implica que los regímenes basados en una voluntad común sean necesariamente democráticos: esta voluntad común puede ser la de la minoría, que supone que puede expresar la voluntad de los otros,

${ }^{25}$ Habría que recordar que la invención francesa de la laicidad empieza con el edicto de Nantes de 1598, en el que se distinguía el sujeto político, que debía obediencia al rey, y el creyente, libre de su elección religiosa, considerada como un asunto privado. No hace falta recordar que la revocación de ese edicto, en 1785, significó un retroceso en la conformación de la libertad religiosa.

${ }^{26}$ Para explicar la historia de la laicidad en Francia, Baubérot propone un modelo interpretativo basado en lo que él llama "umbrales de laicización", cada uno de los cuales tiene características históricas y sociológicas específicas, y que marcan el desarrollo de la construcción de una sociedad cuyas reglas de convivencia se basan en elementos cívicos secularizados (J. Baubérot, op. cit.).

${ }^{27}$ V. Zanone, "Laicismo", p. 885.

${ }^{28}$ R. Blancarte, "Definir la laicidad (desde una perspectiva mexicana)", p. 16.

Diánoia, vol. LI, no. 56 (mayo 2006). 
o que los otros no son capaces de autogobernarse. Puede ser, asimismo, el fundamento de un régimen fascista. En todo caso, el paso importante es que la política se libera de su dependencia de la religión, con lo que el espacio público se seculariza. En el caso de las sociedades democráticas, con la institución del sufragio universal, cuando el pueblo se convierte en única fuente legítima del poder, esta nueva forma de convivencia, por un lado, da fin a la confusión de los poderes políticos y religiosos, suponiendo, por otro, la libertad de conciencia y, por consiguiente, el respeto a las otras libertades modernas: de expresión, de pensamiento y, sobre todo, la libertad de creencias y de culto. Las distintas creencias, así como la no-creencia pueden coexistir como alternativas.

Una razón central del surgimiento del estado laico es la protección de la conciencia frente a las amenazas externas. Desde el punto de vista de la relación entre Estado e Iglesias, las instituciones del estado laico son autónomas con respecto a las organizaciones confesionales. Son neutrales en cuanto que no optan por una creencia particular en detrimento de las demás, sino que garantizan a todos los individuos libertad de religión y de culto, sin establecer entre las religiones ni un sistema de privilegios ni un sistema de control. La doctrina del laicismo sostiene no sólo la separación política y jurídica entre Iglesia y Estado, sino también los derechos individuales de libertad respecto de esos dos poderes. El corazón de la laicidad está en la garantía, ofrecida por el estado, de la libertad de conciencia para todos.

Durante todo el final del siglo XIX y principios del XX domina una visión estrecha de la laicidad que se caracteriza por un rechazo sistemático a toda sujeción religiosa; pero, progresivamente, este clima de hostilidad entre la Iglesia y el Estado dará lugar a un nuevo sentido de la laicidad. Entre los dos modelos de laicidad, uno combativo y anticlerical, por un lado, y uno que defiende la separación respectiva entre el estado y las religiones, partiendo del respeto de todas las opciones religiosas o espirituales, por otro, finalmente llega a imponerse el segundo modelo, más liberal y tolerante. ${ }^{29}$ Así, la ley de 1905 en Francia tiene como objetivo la realización de la paz religiosa, restringiendo los "combates" entre católicos y laicos. Es una ley que privatiza las elecciones religiosas, las creencias y afiliaciones, es decir, las confina al ámbito de la conciencia privada, al espacio privado. Sin embargo, en los términos de la ley, la religión ya no es una cuestión estrictamente privada, en tanto que no retira las manifestaciones religiosas de la vida social, sino

${ }^{29}$ Como dice la Comisión: "En el siglo xx, la laicidad se transforma de bandera de combate en valor republicano compartido." Desde 1958, la laicidad es parte de los principios constitucionales de la República francesa. 
que únicamente se suspende su estatuto público. El derecho francés "garantiza el libre ejercicio de los cultos" (artículo primero), es decir, la libertad del ejercicio público —o sea, abierto, manifiesto- de los cultos está bajo la protección del estado. El principio laico no designa, entonces, la ausencia de la religión, sino el hecho de que la religión ocupa un lugar diferente, compatible con un estado independiente cuya legitimidad no depende de las instituciones eclesiásticas.

Con ello, la Iglesia va adquiriendo poco a poco una mayor libertad, limitada únicamente por el orden público. A partir del periodo entre las dos guerras mundiales, las cuestiones de religión pasan a un segundo plano. Las nuevas preocupaciones, consecuencia de los conflictos sociales y políticos de ese período, alejan la atención de la cuestión religiosa; como resultado, la laicidad deja de ser un instrumento de lucha para volver a adquirir su sentido de laicidad-neutralidad, garantizando el respeto de todas las opciones espirituales desde el liberalismo y la tolerancia, distinguiendo la esfera privada, como ámbito del culto, de la esfera pública-política. Desde un punto de vista jurídico, la recuperación del sentido de la laicidad como neutralidad abre el espacio para las elecciones libres en cuestiones de religión, es decir, el estado renuncia a ser el propagandista de una fe determinada en dos sentidos: esa neutralidad le prohíbe al estado ejercer cualquier tipo de presión que pudiera determinar la opción por una creencia, y, al mismo tiempo, le prescribe el respeto de las opciones libres, sean de un compromiso religioso, sean adhesiones filosóficas o políticas.

En este repaso muy apretado y superficial del desarrollo histórico de la laicidad aparecen algunos de los componentes del principio de la laicidad. Tomando como punto de referencia la propuesta de Blancarte de definir la laicidad en términos de los procesos y formas de legitimidad política, la laicidad sería "un proceso de transición de formas de legitimidad sagradas a formas democráticas o basadas en la voluntad popular". ${ }^{30}$ Hay que constatar, antes que nada, que la laicidad es un proceso, más que una forma fija o acabada en forma definitiva. En cada momento histórico, la laicidad se identifica con la separación del Estado y las Iglesias, con la tolerancia, con la defensa de las libertades individuales. Pero la laicidad no agota su significado en alguno de esos elementos, los cuales pueden existir sin implicar necesariamente la laicidad.

Si en un momento dado la separación entre Estado e Iglesias puede identificarse totalmente con la laicidad, dicha separación no supo-

${ }^{30}$ R. Blancarte, "Definir la laicidad (desde una perspectiva mexicana)", p. 17. 
ne necesariamente la laicidad, ni es condición necesaria para que se reconozca este principio. ${ }^{31}$ En segundo lugar, el reconocimiento de la pluralidad religiosa no implica la laicidad. La idea de libertad religiosa está ligada a la de laicidad, así como al reconocimiento público de la pluralidad, pero no es sinónimo de ellas. La libertad religiosa, reconocida en las primeras Declaraciones, significaba libertad de conciencia, de creencias, de expresión y de culto, y tan no implicaba necesariamente la idea de laicidad, que la religión era considerada como un elemento social necesario para garantizar la convivencia ordenada.

De la misma manera, la tolerancia se liga estrechamente al concepto de laicidad, pero se distingue de éste. La tolerancia nace en el siglo XVI con las guerras de religión entre católicos y protestantes: los católicos terminaron tolerando a los protestantes y éstos últimos a los primeros. Después, la tolerancia fue exigida frente a todas las religiones y todas las creencias, y en el siglo XIX se extendió al pensamiento en general y, por último, a las opiniones políticas. En este proceso, que representa una de las grandes conquistas del mundo occidental, la tolerancia consiste en dejar coexistir diferentes creencias en el marco común del derecho; es decir, para garantizar la tolerancia son necesarias reglas comunes a todos que hagan posible la coexistencia de las libertades. Pero, si bien el estado laico y las instituciones políticas laicas se han constituido en garantes de esas libertades, tolerancia y laicidad no son lo mismo. La tolerancia aumenta con la separación entre el Estado y las Iglesias, pero puede crecer aunque no exista una separación formal o aunque no haya un estado laico. ${ }^{32}$

El renacimiento del conflicto entre laicos y religiosos resurge hoy en un terreno que, en la historia, ha constituido un escenario privilegiado de los enfrentamientos y en el cual el compromiso parecía más frágil: la escuela pública. Recordemos que, en Francia, la esfera pública incluye el sistema de educación pública; la escuela es un instrumento del estado laico para la educación pública de los futuros ciudadanos. Además, si antes se trataba de llegar a establecer ciertas reglas de juego con la religión católica, ahora el problema de la religión en la educación en

${ }^{31}$ Como lo señala el propio Blancarte, hay estados que no reconocen la separación formal entre el Estado y las Iglesias y, sin embargo, sus formas de gobierno son democráticas y, por lo tanto, sustentan su legitimidad en la soberanía popular. También puede haber países formalmente laicos, pero en realidad condicionados por el apoyo político de la Iglesia mayoritaria del país o de varias de ellas. Y existen países que no son formalmente laicos, pero cuya legitimidad no depende las instituciones religiosas (ibid., p. 17).

${ }^{32}$ Es el caso de los países escandinavos o de Inglaterra, por ejemplo. 
general se refiere -en Francia - sobre todo al caso del Islam. Con el asunto de los velos islámicos, volvió a manifestarse el temor de que entre el Estado y el Islam se diera un conflicto similar al que hubo con la religión católica: ${ }^{33}$

[la] desvinculación de la ciudadanía de la religión [.. .] presente en la tradición francesa, la que, como los autores del informe reconocen, ha funcionado históricamente para separar la Iglesia del Estado, y para garantizar la libertad de cultos (católico, protestante, judío), es la que hoy está puesta en cuestión ante la realidad de sectores de una inmigración que no se reconoce en los valores de la república. ${ }^{34}$

La pregunta que se plantea es si el Islam y la laicidad son compatibles, si bien esta oposición no debe exagerarse en virtud de que existe una gran variedad de aspectos del Islam, según su lugar de procedencia. ${ }^{35}$

Ahora bien, el debate en torno al principio de laicidad no es un problema abstracto; detrás de las discusiones en torno al uso del velo se deja sentir un problema de gran peso y dificultad para el Estado francés, que es el de cómo integrar a la población inmigrante musulmana. El papel desempeñado por la educación es fundamental para lograr esa integración, pues es en ese ámbito donde es posible conformar un sentimiento de lealtad a las instituciones, fomentar un vínculo entre los distintos sectores sociales y lograr así una ciudadanía compartida. Pero, además de la educación, la falta de trabajo, la miseria y el aislamiento de los inmigrantes son obstáculos que el estado no ha logrado resolver. De hecho, algo de esto se deja ver en la pregunta planteada por la Comisión: “¿Cómo vivir juntos?” Al intentar responder esta cuestión, mediante una redefinición de la laicidad, aparecen otras cuestiones correlativas que revelan el choque de valores entre la visión

${ }^{33} \mathrm{El}$ Islam es una religión particularmente exigente. Sus textos fundadores son el Corán, palabra de Dios recogida por el Profeta; la Sunna, conjunto de hechos y de sentencias del Profeta; y la Charria, que explicita el conjunto de preceptos que el creyente debe observar en su vida cotidiana: "Por tanto, el Islam no es únicamente una religión, sino que es también un modo de organización de la sociedad civil, siendo inseparables estos dos aspectos" (F. Collet, La Laïcité, une doctrine de l'éducation nationale).

${ }^{34}$ A. García Santesmases, "La 'mala prensa' del laicismo", p. 40.

${ }^{35} \mathrm{El}$ de los países del Magreb es distinto del de los países de Indonesia; el Islam de los sunitas es distinto del Islam chiíta... La opacidad en torno al Islam, segunda religión en Francia, trató de resolverse con la creación del Consejo Consultor de los Musulmanes de Francia, cuyo interlocutor con el gobierno francés es el rector de la Mezquita de París.

Diánoia, vol. LI, no. 56 (mayo 2006). 
laica y la islámica: la igualdad entre hombres y mujeres y la integración de los inmigrados en la escuela. Habría que preguntarse si la laicidad -redefinida o no- es capaz de resolver estos problemas junto con las tendencias hacia el comunitarismo a partir de la defensa de la identidad étnica y cultural, el racismo y las discriminaciones sociales.

\section{Principios de la laicidad}

Frente a estos problemas, intentemos una reformulación del modelo ideal de sociedad laica, siguiendo los argumentos de la Comisión Stasi. La primera prescripción de la doctrina de la laicidad es la defensa de la autonomía del hombre y de las instituciones sociales, en particular del estado, con respecto a toda influencia eclesiástica o religiosa. Por un lado, el estado deberá adoptar una posición neutral en lo que respecta a la religión y proteger al individuo de cualquier interferencia sobre sus propias creencias. De ahí, el término "laicidad" implica el ejercicio libre de la religión: es decir, el estado debe garantizar la libertad de religión como derecho individual de sostener cualquier creencia religiosa; dicha libertad, considerada como uno de los derechos humanos fundamentales en la actualidad, se extiende más allá de la mera libertad de pensamiento, abarcando la libertad de culto y la libertad de congregación religiosa. Por otro lado, la laicidad consiste en no permitir que las Iglesias, representantes de las religiones, interfieran en las responsabilidades del estado. La laicidad es, entonces, una concepción sobre la separación de la Iglesia y del Estado, una separación de las estructuras del estado o del gobierno de las estructuras de las instituciones religiosas. Ello no implica, en la actualidad, algún tipo de hostilidad por parte del estado hacia la religión: es tan sólo una creencia de que el gobierno y las cuestiones políticas deben mantenerse separadas de las organizaciones religiosas y de los asuntos de religión. Significa tanto proteger al gobierno del intento de las organizaciones religiosas de discutir sus asuntos en lo público-político, como resguardar a las organizaciones religiosas de las disputas y controversias políticas.

Si la laicidad se entiende fundamentalmente como neutralidad (con respecto a las religiones), no es fácil responder si el uso del hiyab es contrario o no a ese principio. Los partidarios de una respuesta afirmativa argumentan que el hiyab es el símbolo de la sumisión de la mujer por la religión, que constituye una traducción extremista del ejercicio del culto y que por su carácter ostensible introduce en el seno mismo de las instituciones, y en particular de la escuela pública, consideraciones extrañas a su misión educativa. Los partidarios del velo responderán 
que su uso es un elemento fundamental e indisociable del ejercicio de los preceptos de la Charria, que no usarlo sería una falta grave contra los deberes religiosos "libremente" asumidos por las mujeres que lo usan, que ese velo no constituye para nada un elemento ostentoso o de propaganda, puesto que se trata sólo de un pedazo de tela de color neutro. Estos argumentos podrían multiplicarse al infinito; se trata de un debate sin fin. La discusión sobre el uso del hiyab atravesó a todos los grupos y partidos en Francia: hubo feministas a favor de la diferencia cultural, feministas radicales, izquierdistas que defendían el velo y partidos de izquierda que apoyaban la ley, pero ponían el acento en el desempleo, las otras discriminaciones, el racismo, la no integración.

El núcleo de la controversia es la conciliación entre las aspiraciones de los alumnos islámicos con cierta concepción de la laicidad que no parece poder responder a un reto doble: la laicidad debe gobernar la organización general del sistema educativo, pero no debería tomar la forma de una doctrina de exclusión. Si la laicidad se redefine como la coexistencia pacífica de las diferencias, o como una tolerancia ampliada, frente a un concepto de laicidad más estrecho y riguroso, aparecerían dos concepciones de la escuela. La escuela podría concebirse como un lugar de difusión de los valores universales, de una neutralidad absoluta, cerrada a todas las influencias exteriores, políticas, sociales o religiosas: la escuela sería un lugar de exclusión y de asimilación. O bien, podría ser el lugar donde los niños son considerados con sus diferencias, y la tarea de la escuela sería permitir su expresión: la escuela como un lugar de integración. A partir de estas controversias y enfrentamientos, la Comisión Stasi se propone redefinir la noción de laicidad, tratando de precisar cuáles son sus principios y cómo deben comprenderse en el contexto de la sociedad contemporánea.

\section{El principio de laicidad de la República francesa \\ 6.1. Neutralidad e igualdad ante la ley}

La primera condición de la laicidad es la neutralidad del estado. El respeto a las diferentes opciones espirituales y religiosas supone la independencia entre éstas y el poder político: ni ellas deben tener influencia en el estado, ni éste sobre aquéllas. Esta neutralidad tiene dos implicaciones. Por un lado, neutralidad e igualdad van de la mano: el artículo segundo de la Constitución francesa impone a la República asegurar "la igualdad ante la ley de todos los ciudadanos sin distinción de su origen, raza o religión". Por otro lado, la Administración Pública, sometida al 
poder político, debe ofrecer todas las garantías de la neutralidad: todo funcionario del servicio público tiene un deber de estricta neutralidad; solamente fuera de su servicio, en la esfera privada, el funcionario es libre de manifestar sus opiniones y creencias. Asimismo, también en relación con las finanzas hay una exigencia de neutralidad absoluta: "La República no reconoce, ni paga, ni subvenciona ningún culto."

El segundo principio jurídico de la laicidad es la libertad de conciencia. El estado no puede imponer ningún tipo de restricción en las elecciones filosóficas, políticas o religiosas de los ciudadanos. El estado, en virtud de esa neutralidad y de la igualdad ante la ley de las opciones religiosas y espirituales, no debe privilegiar ninguna de estas opciones. Pero, además, queda protegido y garantizado el libre ejercicio del culto, siempre y cuando no amenace el orden público. En este marco laico, las elecciones espirituales o religiosas dependen de la libertad individual, pero no son relegadas a la intimidad de la conciencia, es decir, no se les niega su capacidad de expresión manifiesta. La libre expresión espiritual o religiosa en el espacio público es esencial para el debate democrático, lo cual es muy distinto del dominio o imposición de una de esas opciones sobre el poder político. El concepto de laicidad representa, entonces, la neutralidad pública y manifiesta del estado con respecto a todo tipo de prácticas religiosas, institucionalizada a través de la eliminación de los símbolos, imágenes y vestimentas religiosos de los espacios públicos oficiales.

El estado laico "protege al individuo y permite libremente a todos elegir, o no, una opción espiritual o religiosa, cambiarla o renunciar a ella. Asegura que ningún grupo, ninguna comunidad pueda imponer a nadie una pertenencia o una identidad confesional, en particular en razón de sus orígenes." ${ }^{36}$ Esta exigencia se aplica sobre todo a la escuela. Los principios de la laicidad en relación con la enseñanza son: a) el respeto de la neutralidad de los programas y de los profesores; b) el respeto de la libertad de conciencia de los alumnos. En la escuela es donde se da la conciliación entre la libertad de conciencia y las exigencias de neutralidad del servicio público. La escuela es el lugar donde los alumnos tienen la posibilidad de construir su autonomía y de ejercer su propio juicio sobre las religiones y la espiritualidad en general.

\section{2. "Exigencia compartida"}

Como decíamos antes, si no hay una intromisión del poder político en las cuestiones de culto, a cambio se exige "un esfuerzo" tanto de

\footnotetext{
36 "Le Rapport de la Commission Stasi sur la Laïcité", punto 1.2.2.
} 
los cultos como de los individuos. Así como en el pasado la religión católica "se esforzó" para adaptarse al mundo de la laicidad, toda religión debería hacer ese mismo esfuerzo, "un esfuerzo interpretativo para conciliar el dogma religioso y las leyes que rigen la sociedad". ${ }^{37}$ Esta exigencia laica no sólo es frente a los cultos, sino también pide que los ciudadanos respeten el espacio público que todos pueden compartir. De hecho, ninguna libertad puede ser efectivamente garantizada si no queda circunscrita dentro de ciertos límites. Así, cuando se declara el derecho de los alumnos a expresar y manifestar sus creencias religiosas, se precisa que esta libertad debe ejercerse respetando el pluralismo y la libertad de los otros. Esta "exigencia compartida", este equilibrio entre derechos y obligaciones, pide "la aceptación tanto de la adaptación de la expresión pública de las particularidades confesionales como el establecimiento de límites a la afirmación de su identidad". ${ }^{38} \mathrm{Y}$ es así como de la libertad de culto, la cual implicaría prima facie reconocer el derecho de libertad de los alumnos a llevar signos religiosos a la escuela, se pasa a la consideración de que el uso de signos que manifiestan una pertenencia religiosa es incompatible con la laicidad, y de ahí a la prohibición del uso de los signos religiosos en la escuela.

\section{3. "Vivir juntos"}

\section{A. El comunitarismo}

Desde hace más o menos treinta años, Francia se ha convertido en un país de gran inmigración, por lo que su composición se ha modificado profundamente. La presencia de millones de extranjeros, con culturas y religiones diferentes de las de la mayoría de los franceses, ha hecho surgir problemas de asimilación o de integración difíciles de resolver. Durante mucho tiempo, las políticas del estado se fundaban en la defensa de la unidad del cuerpo social: la uniformidad se aplicaba por encima de toda expresión de las diferencias, las cuales se percibían como una amenaza. Hoy, a partir del hecho evidente de la inmigración, se reconoce la diversidad. Pero los problemas que se plantean son los de cómo conciliar la integración social y el respeto a la diversidad, cómo afirmar valores comunes y un espacio público compartido con el reconocimiento de las opciones individuales, cómo combatir las tendencias políticas y religiosas extremistas portadoras de proyectos comunitaristas.

La Comisión reconoce que en la actualidad sería "vano negar la fuerza del sentimiento comunitario"; pero afirma con firmeza que "la exa-

${ }^{37}$ Ibid., punto 1.3 .

${ }^{38}$ Ibid. 
cerbación de la identidad cultural no debería erigirse en fanatismo de la diferencia a riesgo de opresión y exclusión". ${ }^{39}$ Desde una perspectiva laica, no puede sorprender el rechazo del comunitarismo. La laicidad supone el compromiso de garantizar a cada uno la posibilidad de emanciparse de sus pertenencias y de sus orígenes, de un pasado no siempre valorado: en una sociedad laica, "cada uno debería poder tomar distancia de la tradición. No hay renuncia a sí mismo, sino un movimiento individual de libertad que permite definirse con relación a sus referencias culturales o espirituales sin estar sometido a ellas". ${ }^{40}$ El marco laico debe ser capaz de lograr la coexistencia en un mismo territorio de individuos que no comparten las mismas convicciones, en lugar de concentrarlos en un mosaico de comunidades cerradas en sí mismas y mutuamente excluyentes.

El espacio público es donde todos somos semejantes, y participar en él en nombre de otra identidad que la que confiere la ciudadanía o la residencia en el territorio nacional, conduce a erigir la diferencia cultural de los miembros del cuerpo social en un objeto político. Esta diferencia que, de hecho, constituye una riqueza, pertenece a la esfera privada y debe mantenerse a distancia de la dimensión público-política.

Para mantener [el pacto republicano] es imprescindible que toda religión haga ese esfuerzo de conciliación entre los dogmas particulares y las leyes sociales y que se reconozca a cada miembro de una comunidad el derecho a distanciarse de la propia religión, el derecho a la diferencia no puede transmutarse en el deber de la pertenencia. ${ }^{41}$

Sin embargo, el problema de fondo no es tanto la expresión en el espacio público de las diferencias, en este caso religiosas, sino el hecho de una inmigración que no se reconoce en los valores de la república. En el caso del velo, el Estado francés busca actuar como el defensor de la emancipación de las mujeres de sus comunidades de origen. Sin embargo, algunas mujeres se oponían al estado no tanto para afirmar sus creencias religiosas o su subordinación sexual, sino para afirmar una identidad independiente de la cultura francesa dominante; el uso del velo era un gesto político, un acto consciente de identificación y de provocación. ${ }^{42}$ De ahí que la comisión considere el comunitarismo como "un peligro" para el estado y que el velo asuma la función de un

${ }^{39}$ Ibid., punto 1.2.4.

${ }^{40} \mathrm{Ibid}$., punto 1.2.4.

${ }^{41}$ A. García Santesmases, "La 'mala prensa' del laicismo", p. 41.

${ }^{42} \mathrm{~S}$. Benhabib, The Claims of Culture. Equality and Diversity in the Global Era, pp 94-100. Refiriéndose al caso de las chicas expulsadas en 1989 por usar el velo 
símbolo de negociación entre las identidades religiosas y culturales islámicas y la cultura occidental. Los inmigrantes marginados y excluidos prefieren encerrarse en la pertenencia comunitaria y buscar en la religión una identidad diferente y, en algún sentido, contraria a las instituciones y al Estado francés, una identidad que no está dispuesta a asumir el concepto fuerte de ciudadanía propio del republicanismo:

Las dificultades de integración de aquellos que han llegado al territorio nacional a lo largo de estos últimos decenios, las condiciones de vida en muchos extrarradios de nuestras ciudades, el paro, el sentimiento de ser objeto de discriminación, de ser apartados de la comunidad nacional, sentimiento que han probado muchos de los que viven en nuestro territorio, explican que se preste condescendiente atención a aquellos que les incitan a combatir lo que consideramos los valores de la república. ${ }^{43}$

¿Cómo lograr que el estado pertenezca a todos los ciudadanos? ¿Cómo evitar la fragmentación de la sociedad? Es claro que la educación laica no puede hacerse cargo de todas estas desigualdades, aunque sí puede ayudar, y mucho, al aprendizaje de la ciudadanía.

La discriminación es un hecho; y también es un hecho que encierra a los individuos en sus múltiples identidades. Pero, al afirmar de manera positiva esta identidad, se le da una forma de validación formal: los prejuicios se convierten en razones objetivas, y hay un avance de las discriminaciones fundadas en el sexo o los orígenes. La escuela pública, como instrumento del estado laico, puede ayudar a un aprendizaje de la ciudadanía, a un intercambio de las culturas, a un respeto a las diferencias, manteniendo el espacio escolar público como un espacio libre de confesionalismos. Una vez más, la Comisión muestra su confianza en el principio de la laicidad:

la laicidad puede ser la semilla de la integración de todos en la sociedad: equilibra el reconocimiento del derecho a una identidad propia y el esfuerzo necesario para tejer las convicciones individuales en los lazos sociales. La enseñanza de la ciudadanía en nuestra sociedad a culturas y orígenes diversos supone que se aprenda a vivir juntos. $\mathrm{Al}$ articular la unidad nacional, la neutralidad de la República y el reconocimiento de la diversidad, la

en la escuela, la autora señala que, al usar el velo, "Fátima, Leila y Samira, por un lado, sostenían que ejercían su libertad de religión como ciudadanas francesas; por el otro lado, exhibían sus orígenes musulmanes y de África del Norte en un contexto que buscaba envolverlas, como estudiantes de la nación, en un ideal de ciudadanía republicano igualitario y secularizado" (p. 96).

43 “Le Rapport de la Commission Stasi sur la Laïcité", punto 1.3.

Diánoia, vol. LI, no. 56 (mayo 2006). 
laicidad crea, más allá de las comunidades tradicionales de cada uno, la comunidad de afectos, ese conjunto de imágenes, de valores, de sueños y de verdades que fundan la República. Cuando la laicidad entra en crisis, la sociedad francesa apenas si puede ofrecer un destino común. Y a la inversa, es posible forjarlo al buscar nuevas formulaciones y traducciones concretas de la laicidad contemporánea. ${ }^{44}$

\section{B. La igualdad entre hombres y mujeres}

El derecho fundamental menos respetado detrás de este asunto del velo es la igualdad entre hombres y mujeres. A pesar de que uno de los principales motivos de la Comisión para proponer la ley contra el uso de los signos religiosos es que el velo islámico es un símbolo de la sumisión de la mujer musulmana, en su argumentación en torno a la defensa del valor de la igualdad parece borrarse la desigualdad entre hombres y mujeres. Para empezar, habría que preguntarse si el velo es simplemente un "símbolo" del trato desigual de la mujer o si no se trata más bien de una cuestión de hecho. El velo es, antes que nada, la expresión de una religión y tiene un significado muy específico: exige a la mujer que se esconda, que oculte su cuerpo, con el fin de no ser una tentación para el hombre. El uso del velo está acompañado, con frecuencia, de vestidos largos, medias gruesas, colores oscuros y la prohibición de que las jóvenes salgan, que practiquen un deporte, que sean atendidas por un médico varón, etc. No se trata simplemente de un modo de vestir, sino de la negación de la mujer como tal. El uso del velo no es sino una parte del proceso de encierro de las mujeres y de su sexo. Y no sólo el Islam inculca la sumisión de la mujer y la superioridad del hombre; la religión católica también decreta, desde las Escrituras, que la mujer es inferior, impura, portadora del pecado original, y es relegada al rango de reproductora; el Papa interviene en la vida pública y política como jefe de Estado con el fin de imponer prohibiciones que son atentados contra la libertad de las mujeres: el divorcio, el aborto, la contracepción, el preservativo.

El planteamiento del problema del uso del velo, desde el punto de vista de la Comisión, muestra dos tensiones que ponen en juego valores distintos. Por un lado, el estado tendría que gestionar la tensión que existe entre el respeto a las diferencias y el orden del espacio público. Por otro lado, hay una tensión entre el derecho a la libertad del individuo y la capacidad del estado de "proteger" ese derecho a través de la prohibición. Recordemos que el fundamento de la unidad nacional

${ }^{44}$ Ibid., punto 1.2.4. 
y la garantía de las libertades individuales es, justamente, la laicidad. Las jóvenes que usaban el velo utilizaban las libertades que les ofrecía el Estado francés, siendo una de ellas la educación pública gratuita para todos los niños en suelo francés, para sobreponer un aspecto de su identidad privada en el espacio público. Además de cuestionar los límites entre lo público y lo privado,

problematizaban tanto la escuela como sus hogares: ya no trataban a la escuela como el espacio neutral de la aculturación francesa, sino que manifestaban abiertamente sus diferencias culturales y religiosas. Utilizaban el símbolo de la casa en la esfera pública, manteniendo la modestia exigida por el Islam al cubrir sus cabezas; y, sin embargo, al mismo tiempo se alejaban del hogar para convertirse en actores públicos en un espacio público civil, en el que desafiaban al Estado. Aquellos que veían en las acciones de las jóvenes simplemente una indicación de su opresión eran tan ciegos al significado simbólico de sus actos como aquellos que defendían sus derechos simplemente sobre la base de su libertad de religión. ${ }^{45}$

En cuanto al respeto a las diferencias, a partir de la Declaración de 1789 , la igualdad ya no es considerada como un hecho, sino como un valor: de hecho, los seres humanos son diferentes y lo que se busca es impedir que sus diferencias pesen como factores de desigualdad.

"Igualdad" es un término normativo: quiere decir que los "diferentes" deben ser respetados y tratados como iguales; y que, siendo ésta una norma, no basta enunciarla sino que es necesario observarla y sancionarla. "Diferencia(s)" es un término descriptivo: quiere decir que de hecho, entre las personas, hay diferencias, que la identidad de cada persona está dada, precisamente, por sus diferencias, y que son, pues, sus diferencias las que deben ser tuteladas, respetadas y garantizadas en obsequio al principio de igualdad. ${ }^{46}$

Si bien, con mucha frecuencia, la igualdad es violada, resultando inefectiva en el tratamiento de las diferencias y dando lugar a discriminaciones de mujeres, trabajadores e inmigrantes, las identidades - las diferencias naturales o culturales - de cada persona son (o deberían ser) tuteladas por el principio de la igualdad formal. A través de este principio todos son ciudadanos, y todos deben ser respetados. El orden en el espacio público dependerá, en gran media, del respeto al principio de igualdad.

${ }^{45}$ S. Benhabib, op. cit., p. 97.

${ }^{46}$ L. Ferrajoli, Derechos y garantías. La ley del más débil, p. 79. 
El razonamiento de la Comisión es que, al prohibir el uso del velo, el estado estaría cumpliendo su tarea de proteger y garantizar la igualdad entre hombres y mujeres, pues estaría "obligando" a las chicas musulmanas a la experiencia de comportarse y de ser iguales a los varones, de no usar un símbolo que las marca como sexualmente inferiores; al mismo tiempo, estaría manteniendo el orden necesario para la convivencia en el espacio público.

\section{7. ¿Es la ley la solución a los problemas de la laicidad?}

Como hemos visto, el conflicto entre católicos y "republicanos" ha desaparecido. El problema es si hay que prohibir mediante una ley las manifestaciones de una creencia religiosa; si la cuestión se plantea en estos términos, es evidente que la respuesta tiene que ser negativa; si se plantea en los términos de las conclusiones a las que llega la Comisión Stasi, de no sólo defender el respeto de las creencias y las prácticas, sino de evitar el sectarismo y el repliegue comunitario que con frecuencia conduce a resaltar aspectos antilaicos de la vida real, entonces la respuesta es afirmativa. Pero veamos, a modo de conclusión, algunos de los argumentos que se dieron a favor y en contra de la ley sobre la prohibición del uso de signos religiosos ostensibles en la escuela pública.

Por un lado, la ley se consideraba como necesaria por una cuestión de principios: se trataba de recuperar la neutralidad de la escuela, de preservarla de las pertenencias religiosas. En este sentido, la escuela no debe admitir ningún signo, como el hiyab, que distingue a sus portadoras como pertenecientes a la religión islámica y como mujeres, simbolizando así su estatus de inferioridad con respecto al hombre. Se trataba de actuar antes de que la situación se volviera incontrolable, y la ley aparecía como el único medio capaz de tener la autoridad necesaria para la afirmación de los valores laicos. Pero ¿́puede demostrarse de manera razonable que el uso del velo tiene el efecto de introducir un elemento de presión y que perturba la enseñanza? Parecería que no, y que lo que justificaría las decisiones de excluir a las jóvenes con velo sería otra cosa: la amenaza que representa el uso del velo para la escuela y, en última instancia, para la República. La tolerancia, vinculada a la laicidad, puede ser restringida únicamente por razones cuya legitimidad no puede dudarse, y no en nombre de inquietudes o sospechas de peligro para las instituciones públicas. Finalmente, la neutralidad de la escuela pública consiste, por un lado, en el rechazo a otorgar privilegios por el hecho de pertenecer a alguna religión particular, y, por el otro, en 
la ausencia de toda referencia religiosa en la enseñanza. Los profesores, al igual que cualquier otro servidor público, no pueden manifestar en el ejercicio de sus funciones ninguna preferencia religiosa. Pero itiene sentido exigirles la misma neutralidad, la misma laicidad, a los alumnos? La escuela, en efecto, puede conducir al alumno a emanciparse de sus pertenencias particulares; pero ¿debe exigirle desde el principio un compromiso con la laicidad? En la escuela, a través de la experiencia del diálogo y del conocimiento, los alumnos aprenden a ser laicos, justamente porque no se ven obligados a creer en ciertos principios por autoridad. La escuela es el lugar de formación de individuos autónomos: es ahí donde se aprende a dialogar, a confrontar sus ideas con las de los otros, a establecer juicios autónomos. La pregunta que queda abierta es si la escuela no debería ser justamente el espacio de igualación laica a partir de las diferencias de origen, en lugar de plantear la cuestión del velo como un mecanismo de exclusión, con el riesgo de condenar a esas jóvenes a quedar presas de su condición.

En relación con la igualdad de los sexos, hay que reconocer que el velo no es un simple pedazo de tela sobre la cabeza: simboliza la sujeción de la mujer. En la escuela, el principio de no discriminación entre mujer y hombre es básico, y parecería que el velo atenta directamente contra él; pero, al mismo tiempo que el velo "marca" a las mujeres como mujeres, es decir, como inferiores a los hombres, los profesores y los otros alumnos las tratan como iguales: "el sentido más profundo de la exigencia de igualdad en la escuela reside ahí: permitir que las chicas accedan a esta forma de vida donde son tratadas como iguales $[\ldots .$.$] . Excluirlas es [...] decidir deliberadamente no tratarlas como a los$ otros." 47

Algunas chicas son obligadas a usar el velo o incitadas a ello desde su infancia; otras deciden no usarlo para desmarcarse de su comunidad. Las primeras aceptan una forma de sometimiento de la mujer, pero parecería que lo hacen libremente. La escuela no puede emanciparlas contra su voluntad, pidiéndoles que renuncien a lo que libremente (aunque de esto se pueda dudar) eligieron: "Es contradictorio desear que las chicas encuentren verdaderos recursos de autonomía cuando se empieza por imponerles, contra su voluntad, renunciar a su elección religiosa." 48

Por lo que respecta al comunitarismo, la ley sobre el uso de los signos religiosos no resuelve el problema. Muchas de las "pasiones" o compor-

\footnotetext{
${ }^{47}$ M. Canto-Sperber y P. Ricoeur, "Une Laïcité d'exclusion est le meilleur ennemi de l'égalité".

${ }^{48}$ Ibid.
} 
tamientos peligrosos y fanáticos del islamismo son resultado del resentimiento que experimentan los musulmanes por el hecho de su propia historia y por el lugar que se les da en las sociedades europeas. La discriminación de la que son víctimas, consecuencia de lo que Ferrajoli ha llamado el "racismo institucional", mediante el cual las relaciones con los "otros" son instauradas como relaciones de dominación, producen "una regresión de nuestras propias identidades nacionales, como identidades cerradas a la confrontación con otras culturas y cimentadas por la aversión contra el que es distinto". ${ }^{49}$ En el fondo, como decíamos antes, el problema que subyace es la posibilidad de convivir con los millones ${ }^{50}$ de musulmanes que viven en territorio francés, con todos los problemas que ello plantea: vivienda, trabajo, cultura, salud, etc. La República debería más bien reflexionar qué y cuánto de esa realidad de millones de inmigrantes puede realmente incorporar y procesar. La cuestión del velo, en esta perspectiva, aparece no como un elemento de integración, sino como un mero mecanismo de exclusión que no refuerza el principio de la laicidad: "el debate sobre el velo oculta o evita pensar la situación de los más desprovistos: oculta un mal que ya no se quiere ver, el de la nueva cuestión social". ${ }^{51}$

¿Era necesaria la ley? Después de revisar algunas de las críticas contra la prohibición de los signos religiosos, a partir del documento de la Comisión Stasi, resulta difícil tener una posición clara frente a este conflicto. Podemos afirmar que el Estado francés nunca perdió de vista la necesidad de conciliar dos principios: la laicidad y la libertad de religión y de conciencia. Por ello se debían respetar tanto la laicidad y la neutralidad del estado en los servicios públicos, como la libertad de conciencia de las estudiantes. Y es esto último lo que plantea más dudas. Sin embargo, si el uso del velo se ve como un medio de provocación política, la libertad de conciencia queda a salvo y la ley está justificada. Por otra parte, se subrayó con fuerza el principio según el cual toda discriminación basada sobre creencias religiosas de las estudiantes sería inadmisible: es decir, en ningún momento se pensó que la exclusión de las jóvenes de la escuela era una solución. En suma, el factor decisivo para la restricción de la libertad de religión de las estudiantes no fueron sus creencias sobre el significado religioso del velo, sino el modo como las autoridades escolares interpretaron ese significado, concluyendo que el uso del velo era un medio de provocación.

${ }^{49}$ L. Ferrajoli, "Libertad e inmigración", p. 48.

${ }^{50}$ Se estima que el número de musulmanes en Francia oscila entre los tres y los cinco millones (Le Monde, 19 de diciembre de 2003).

${ }^{51}$ D. Cohen, "Le Voile de l'ignorance". 
La discusión a la que ha dado lugar el conflicto desatado por el uso del velo ha ido mucho más allá que el asunto puntual, dejando muchas preguntas abiertas. Tanto la izquierda como la derecha debaten sobre los significados del republicanismo francés, sobre la igualdad social y sexual, así como sobre la contraposición o relación entre liberalismo y multiculturalismo:

El asunto del velo finalmente llegó a representar todos los dilemas de la identidad nacional francesa en una época de globalización y multiculturalismo: cómo mantener las tradiciones francesas de laicidad, igualdad republicana y ciudadanía democrática frente a la integración de Francia en la Unión Europea, por un lado, y las presiones del multiculturalismo generadas por la presencia de la segunda y la tercera generaciones de emigrados de los países musulmanes en suelo francés, por el otro. [...] Es evidente que este asunto no ha terminado. Mientras duren las presiones de la integración europea y del multiculturalismo, Francia [.. .] tendrá que descubrir nuevos modelos de instituciones legales, pedagógicas, sociales y culturales para tratar con el doble imperativo de las democracias liberales de preservar la libertad de expresión religiosa y los principios del secularismo. ${ }^{52}$

El asunto del velo revela, pues, que el problema tiene muchas aristas y, en ese sentido, la ley que prohíbe su uso es importante para definir el significado de la laicidad en la vida escolar, pero parece una solución parcial cuando se mira en el contexto más amplio de la nueva agenda social. Se trata de una cuestión complicada que exigiría al estado tomar distintas vías para resolverla. La prohibición funcionó más como una política de emergencia que no debería sustituir la creación de un conjunto de políticas internas y externas, capaces de construir una conciencia de pertenencia común y de fortalecer las condiciones que hacen posible el diálogo y la convivencia civilizada.

\section{BIBLIOGRAFÍA}

Baubérot, J., Historia de la laicidad francesa, El Colegio Mexiquense, México, 2005.

Benhabib, S., The Claims of Culture. Equality and Diversity in the Global Era, Princeton University Press, Princeton, 2002.

Bobbio, N., "Cultura laica, una terza cultura?", en AA.VV., Colloqui a Torino: cattolici, laici, marxisti attraverso la crisi, Stampatori, Turín, 1978, pp. 28-42.

${ }^{52}$ S. Benhabib, op. cit., p. 100.

Diánoia, vol. LI, no. 56 (mayo 2006). 
Bobbio, N., "La tolleranza positiva", entrevista de C. Ottino a Norberto Bobbio, L'Isola del libro, 1994, pp. 12-14; se encuentra disponible en el catálogo del Centro Studi Piero Gobetti: http://www.erasmo.it/gobetti/f_catalog.asp.

Bobbio, N., "Le ragioni della tolleranza", en N. Bobbio, L'età dei diritti, Einaudi, Turín, 1990, pp. 235-252.

Blancarte, R., "Definir la laicidad (desde una perspectiva mexicana)", Revista Internacional de Filosofía Política, no. 24, 2004, pp. 15-28.

—_, "Introducción", en Laicidad y valores en un Estado democrático, Secretaría de Gobernación-El Colegio de México, México, 2000.

Canto-Sperber, M. y P. Ricoeur, "Une Laïcité d'exclusion est le meilleur ennemi de l'égalité", Le Monde, 11 de diciembre de 2003.

Cohen, D., "Le Voile de l'ignorance", Le Monde, 16 de febrero de 2004.

Collet, F., La Laïcité, une doctrine de l'éducation nationale, tesis para obtener el Diplôme d'Études Approfondies (DEA), Facultad de Derecho de la Universidad de Grenoble, 1995.

Comisión Stasi, "Le Rapport de la Commission Stasi sur la Laïcité", en Le Monde, 12 de diciembre de 2003. [Versión en castellano: "Informe para el presidente de la República. Comisión de reflexión sobre la aplicación del principio del laicismo en la República" (mimeo).]

De Lucas, Javier, “¿Para dejar de hablar de la tolerancia?”, Doxa. Cuadernos de Filosofía del Derecho, no. 11, 1992, pp. 117-126.

Ferrajoli, L., Derecho y razón. Teoría del galantismo penal, trad. Perfecto Andrés Ibáñez, Trotta, Madrid, 1997.

— Derechos y garantías. La ley del más débil, trad. Andrea Greppi, introd. Perfecto Andrés Ibáñez; Madrid, Trotta, 1999.

—, "Libertad e inmigración", Revista Internacional de Filosofía Política, no. 22, 2004, pp. 41-52.

García Santesmases, A., "La 'mala prensa' del laicismo", Revista Internacional de Filosofía Política, no. 24, 2005, pp. 29-46.

Giddens, A., "Voile islamique: la France sur la mauvaise voie", Le Monde, 14 de enero de 2004.

Kintzler, C., Tolérance et laïcité, Pleins Feux, París, 1998.

Rabotnikof, N., En busca de un lugar común. El espacio público en la teoría política contemporánea, Instituto de Investigaciones Filosóficas-UNAM, México, 2005.

Vitale, E., Derechos y paz. Destinos individuales y colectivos, trad. Pedro Salazar Ugarte, Fontamara, México, 2004.

_

Zanone, V., "Laicismo", en N. Bobbio y N. Matteucci (eds.), Diccionario de política, Siglo XXI, México, 1982.

Recibido el 15 de diciembre de 2004; aceptado el 29 de noviembre de 2005. 